\title{
THE STUDY OF POPULATION ECOLOGY APPROACH TO ORGANIZATION
}

\author{
Alireza Amirkabiri \\ Department of management, Central Tehran Branch, Islamic Azad University, Tehran, Iran \\ Meysam Eyvazi \\ Phd candidate of public administration, Central Tehran Branch, Islamic Azad University, Tehran, Iran \\ mhrdade@yahoo.com \\ Mahbobe Haji Mirzaie \\ Phd candidate of public administration, Central Tehran Branch, Islamic Azad University, Tehran, Iran \\ Morteza Kheirkhah \\ Phd candidate of public administration, Central Tehran Branch, Islamic Azad University, Tehran, Iran
}

\begin{abstract}
Since every school of thought wants - to quote Neil Austin Flig (1985) explain the phenomenon organization from your point of view - in this study, we have some interesting discussions about population ecology approach (approach of organizational population environment) on behalf of the elders of this approach is provided with the express criticism on it. In this study, the meaning of ecology and its history, divisions of ecology, environment and natural selection, Relationships with their environment in a particular branch of industry or in a given area, the hardness and stability, factors that organizations containers hard work and organizations cannot easily do transfers resources and principles do not change, Ecological approach to change in organizations and the impact of aging on their failure to adapt to the environment, the fundamental logic approach to the theory of ecology and criticisms that has been discussed and concluded. This paper reviews the theory of ecology of organizations.
\end{abstract}

Keywords: population ecology, organizational ecology, organizational relations

\section{INTRODUCTION}

In recent years a growing interest in the formation, growth and decline has been more of an organization, according to the theory result of these discussions has grown. Therefore, before moving in this direction should look at both macro and micro analysis. Population ecology theory seeks to explain the birth, growth and death through the natural process variation, selection, retention and competition. Hence, we study the population dynamics of the organization with a face that it is a kind of characteristic of this theory. Population ecology or natural selection since 1940, was considered in social systems, but the best definition of it has been presented Hanan and Freeman and Aldrich (1979). Principles of population ecology population and organizations trying to justify why lump of organizational forms remain and others disappear (1).

From 1979 to 1989, 187 organizations listed in Fortune magazine, 500 organizations were excluded from the list and do not exist as independent organizations. Some of them were bought by other organizations and some other organizations Shdand integration. A number also have been bankrupt. Due to removal of these organizations, their inability to adapt to environmental changes and meet the needs of the environment (2).

It requires a dynamic organizational culture appropriate to the environment was turbulent. Instead, new institutions were created that were adapted to the current environment and can meet the specific needs of organizations and overtaking previous kidnapping (2). In theory it is assumed that the 
perimeter of a corporate organizational population ecology of power that you can choose from among a group of organizations competing organizations that best meet the needs of the environment. It may be concluded that Darwin's theory of survival of the fittest principle of such organizations (3). Population ecology is a framework for understanding organizational changes based on natural selection process that is described in the bio-ecology as any in the natural world.

Organizations in various forms with the structure, goals and live their own production or operations. Successful organizations by setting chosen on the basis of sustainability and environmental protection (Alexander and Kaluzny and Middleton 304: 1986) (4). Organizational population ecology theory raises questions about how come there are also several reasons, and the fact that how arise in the form of numerous organizations. It is trying to respond to the erupting questions that organizations around the world look at the similarities as well as the biodiversity of nature in the world. This diversity can be explained according to the theory of evolution. This theory has been around since 1975 as a critical theory in the organization. Also, this theory also states that the decision-making managers aware of the environment is based on natural selection (1).

Dependence on the density of the population (the population) to be considered as limiting the amount of the environmental source. The population is growing naturally or are entering a new or growing organizations. However, this growth limited resources. On the other hand, competition is a dynamic process. Congestion is increasing industry continues to destroy the legitimacy of competitive pressures and reduce the rate of installation failure rate. Population density has been shown by many studies of the relationship between the company lives with possibility (3).

The researchers also found that using data based on the empirical study of published research that "If a society already has with community organizations or communities are more entrepreneurial behavior of community members representing different behavior is manifested by the theory of population ecology" and, also, similarly, in this context, the information shown represents the community easier and Entrepreneurship has been more than others in the birth rate.

\section{STRUCTURAL STILLNESS}

The concept ecology concept structural rigidity and stagnation or inactivity. The "hardness and stability" for various reasons lose the ability to change and move to a living organism (organization), i.e., for "rigid" states that "motionless" stay. This is similar to a rigidity and hardness that occur in the human body. All the various organs in the human body for reasons such as arthritis and atherosclerosis lose their ability to move and flex. As a result, unable to respond to the changing requirements of environmental damage. This can sometimes be the end of its life living organism. Business organizations also arise for various reasons an Event "stiffness and hardness" (5).

Organizers are born with a certain shape and unable to change its constitution to deal with environmental threats. Structural stasis stems from several factors, internal and external pressure. Internal factors include:

1. The organization's investment in the plant, and equipment and dedicated professional staff can easily transfer to other duties and functions.

2. .2tsmym makers in organizations do not get comprehensive information about its internal activities or environmental requirements, the sub-unit organizations have faced.

3. There is a strong political constraint against change, because change may reduce the power of organized groups and increase the power of other groups. This may convince the opposition of senior decision makers who prefer to rest the problems caused by the change.

4. Finally, organizations are faced with limitations due to his past. Once agreed standards and procedures for assigning tasks and authority and become the norm, much reduced cost to change them (5).

\section{DEMOGRAPHIC CONSTRAINTS}

definition of fit is a problem (environmental conservation is explained on the basis of fitness, but fitness is defined as survival). At the core of organizational population ecology theory was overstated that we cannot predict survival based on the independent evaluation of environmental suitability.

It is usually used for those populations that are very competitive organization. All organizational population not fit the definition. This definition does not fit in populations that are faced with barriers 
to entry or multiple output, such as high start-up costs (eg production) or legal regulations (for example pharmaceuticals). Also, environments that are dominated by a few large organizations, such as large computer manufacturing industry, institutional population are unsuitable for population studies (3).

\section{EXTERNAL PRESSURE TO BRING THE STATIONARY TO ORGANIZATION}

1. legal and financial obstacles in the way of entering the market and there are many of them spend.

2. information about the environment outside the organization may be costly.

3. Organizational rationality requires that an organization may adapt itself to a certain way with the environment (2).

\section{STRATEGIES FOR SURVIVAL}

There is another principle in the demographics of organizations trying to survive or compete. Organizations and organizational populations are often in competition with each other for resources, and the organization attempts to somehow continue to exist. In terms of demographics, organization and due to the efforts of organizations do to survive, strategies should be divided into two categories: public and private. Organizations that have the resources or extensive areas, i.e., those who can offer a very wide variety of products and services to market, fall in public organizations.

Population ecology offers a different perspective to the managers of organizations (see external to the organization) than is normally used. Demography is useful perspective to communicate with members of the government or regulators and supervisors that they naturally look is defined by the level of environmental analysis (due to the large number of organizations affected by their policies) (4).

\section{OPTIMIZATION AND PROCEDURAL LAW IN ECOLOGY APPROACH}

Another concept that arises in connection with optimized ecological approach. In this approach, is the optimizer (Optimizer). Environment (nature) to optimize their right to make a choice (choice) among the units that are in his heart i.e., the environment, selects and removes some organizations in the amount proportionate to the objective features and their attributes. Finally, the main concept is the idea of "uniformity" that can be termed it "the shape or consistency". Uniformity or consistency in the sense that there is a type of organism according to the type and characteristics of the environment (compatible) and "uniform" with these requirements.

Environment that eliminates the organism does not adapt to it, and select those that will adapt and provides the possibility of life for them. As a result, there are common features among businesses that life becomes possible. Businesses have started to uniform up. Diversity of organisms that event in terms of diversity of environmental conditions (5).

\section{DEMOGRAPHIC PERSPECTIVE CONSTRAINTS}

There are also restrictions on the use of demographic perspective. One limitation is defined as the proportion of a problem. This problem also exists in Darwin's theory. (environmental conservation is explained on the basis of fitness, but fitness is defined as survival). At the core of organizational population ecology theory was overstated that we cannot predict survival based on the independent evaluation of environmental suitability. Survival time know to see it (1).

\section{ECOLOGY INTER-ORGANIZATIONAL IN USE}

Ecology is the study of the relationship between the organization and how people like (identical) and that includes communities are heterogeneous, their mutual relationship with each other. And how they have adapted themselves collectively and collectively with the environment. Organizational society is a group of the population and individuals that are determined by the relationship of ecology from the coexistence of two groups two different groups together and living together. Such as units of the same tasks. And includes potential competition between people who have a reciprocal relationship. The competition between individuals depends on the degree of similarity and feed people who are involved. Community people may be limited to a geographical area (e.g., Silicon Valley) are limited 
or economic system can include national, regional, or global are linked to the core and technical center or organization (for example, groups telecommunications). So, studying the social dynamics needs to analyze the processes that underpin the creation and transfer of individuals and populations organization, and thereby, in general, affect the social stability. Assessment and review of the literature to define the sociodemographic, as component (element) is assumed to be the same key communities and distinct organizational forms. Although there is considerable contradiction of ideas about how corporate social and organizational forms to be defined. Multiple definitions have discussed different approaches to classification according to the organization in the literature review. In this study, the organizational ecologists have defined population this way: Categories of actors in understanding the discontinuities in the general sense of social identity. For example, ecologists and artists are dealing with industrial communities with different categories of newspapers (daily vs. weekly) (4).

\section{CONCLUSION}

At the present time, which is an indicator of the dynamics of communities, there is a need to strengthen the dynamic look. Hence, the ecosystem approach is an organization look at the underlying ecological movement in the course of evolution excellence and organizational relationships. Growth in a competitive environment causes increased likelihood of survival and causes of the changing conditions of the environment.

\section{REFERENCES}

1-Rahmanseresht, Hussein, Eddie Firouz Jaei, M, Ghasemi, H. (2011), Review of General Electric to use in the organization, police bimonthly human development, Issue 34.

2-Daft, Richard L. (2010). Theoretical and organizational design, translation Parsaeian, Ali, Arabs, SM, Fifth Edition, Tehran: Cultural Research Bureau.

3-Joe Hetch, Marie (2014). Modern organization theory: the symbolic - and post-modern interpretation, translation Danaeefard, Hassan, Sixth Edition, Tehran: Ketab Mehraban institute.

4-Alexander, A. kaluzny, O, and middeleton, B. (1986), organization growth .survival and death in the US Uhospital industry :population ecology perspective,Sm.Sci. Med. Vol .22.No.3. pp.3-321.

5-Amir Kabir, A. (2013). Approaches to organization and management and organizational behavior (Outlook postmodern), third edition, Tehran: look at knowledge. 